\title{
Sub-inertial variability in the Cretan Sea from the M3A buoy
}

\author{
V. $\operatorname{Cardin}^{1}$, M. Gačić ${ }^{1}$, K. Nittis ${ }^{2}$, V. Kovačević ${ }^{1}$, and L. Perini ${ }^{1}$ \\ ${ }^{1}$ Istituto Nazionale di Oceanografia e di Geofisica Sperimentale OGS, Italy \\ ${ }^{2}$ National Centre for Marine Research, Institute of Oceanography, Athens, Greece
}

Received: 6 September 2001 - Revised: 1 June 2002 - Accepted: 23 July 2002

\begin{abstract}
One year of continuous records of temperature, salinity data at various depths, and currents obtained from by an upward looking acoustic Doppler current profiler (ADCP) moored at a site in the Cretan Sea were analyzed. Temperature and salinity data revealed the influence of a multi-scale circulation pattern prevailing in this area. This pattern consists of mesoscale cyclonic and anticyclonic vortices moving together as a dipole, and inducing downwelling and upwelling in the water column. The dipole movements, which control the circulation in the area, have been evidenced from horizontal current variability in the upper $250 \mathrm{~m}$. The basinscale circulation also shows a prominent seasonal variability. The Empirical Orthogonal Function analysis applied to either zonal or meridional components of the currents, confirmed the prevalence of a depth-independent mode over the baroclinic-like one for the whole period of measurements and for both current components. Nevertheless, the depthdependent structure indicated the out-of-phase behaviour of the upper $250 \mathrm{~m}$ layer with respect to the deeper one. The first mode of the temperature EOF analysis, which accounts for most of the variance, represents the seasonal heating of the water column being principally associated with the surface mixed layer at the level of the seasonal thermocline.
\end{abstract}

Key words. Oceanography: physical (currents, eddies and mesoscale processes, general circulation)

\section{Introduction}

Continuous measurements of some oceanographic parameters and their transmission in real time have been one of the main requirements for running an operational forecasting system. Since the overall Mediterranean Forecasting System's (MFS) goal was to explore, model and quantify the potential predictability of the ecosystem fluctuation at the level of primary producers in the entire basin and coastal/shelf areas, a scheme having the above-mentioned characteristics

Correspondence to: V. Cardin (vcardin@ogs.trieste.it) has become necessary. In order to achieve this objective, moored equipment for the continuous measurement of physical and biogeochemical parameters in the surface and intermediate layers was deployed during the pilot phase of the MFS.

The Cretan Sea (Southern Aegean) was chosen as the location for mooring the "Mediterranean Moored Multiparametric Array" (M3A). There are several criteria for the selection of the mooring site, among them the biogeochemical characteristics of an open ocean oligotrophic area of the Mediterranean Sea. The Cretan Sea is characterised by complex dynamical features, and plays a significant role in the hydrology of the Eastern Mediterranean, as it is a site where both intermediate and deep-water masses are formed (Georgopoulos et al., 1989; Roether et al., 1996). Moreover, it is considered the source of recent changes in the deep thermohaline circulation in the Eastern Mediterranean (Theocharis et al., 1992; Theocharis et al., 1996). Morphologically, it constitutes the largest and the deepest basin of the south Aegean, with an average depth of $1000 \mathrm{~m}$ and contains two depressions in the eastern part, which reach $2500 \mathrm{~m}$. It is bounded to the north by the Kiklades Plateau with a depth of $400 \mathrm{~m}$ and to the south by the Cretan Arc Islands.

The area was extensively investigated in the past in the framework of international programs as POEM (1987-88), PELAGOS (1994-95) and CINCS (1994-95), the latter two carried out during MAST 2 and 3 projects. Principally, circulation patterns and water mass exchanges between the south Aegean, the eastern Ionian and the northwest Levantine basin were studied. These studies led to new circulation concepts for the central region of the Eastern Mediterranean as being characterised by the existence of three scales of motions: the basin, the sub-basin and the mesoscale $(20-30 \mathrm{~km})$ (The Poem Group 1992; Theocharis et al., 1993; Theocharis et al., 1999b). Cyclonic and anticyclonic vortices, fed and interconnected by currents and jets, populate the south Aegean Sea and the adjacent sea regions of the eastern Ionian and northwestern Levantine. They show a variability consisting of a shift of the centers, oscillation of gyres, meanders, 

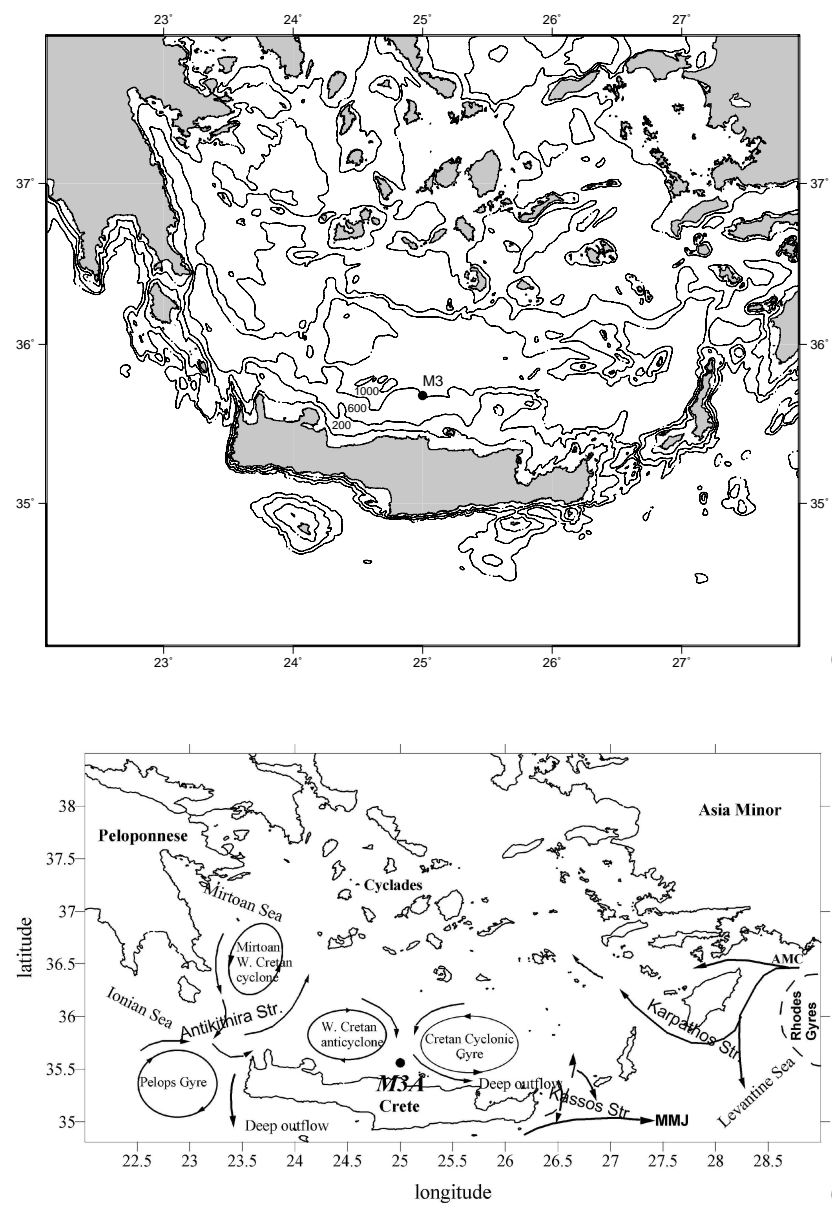

(b)

Fig. 1. (a) Bathymetric chart of the Cretan Sea and (b) Location of the M3A (dot) buoy and schematic configuration of the main upper thermocline circulation features (modified from Theocharis et al., 1999b).

branching and reversal of currents, which evolve at different time scales, from synoptic to interannual. The flow pattern is confined to within the basins' boundaries, which results in the development of dynamical structures with dimensions ranging from some $15-20 \mathrm{~km}$ to $100-250 \mathrm{~km}$ (Theocharis et al., 1999b). Some of the features appeared to be permanent, whereas others were transitional or recurrent. The West Cretan Anticyclone and the Cretan Cyclonic gyre seem to control the circulation, as well as water mass formation and spreading, and the interaction with other basins. In Fig. 1 (from Theocharis et al., 1999b), a schematic configuration of the main upper thermocline circulation features is shown. Unfortunately, no schematic configuration for the intermediate and deep circulation is available in literature. According to the authors, the circulation at $300 \mathrm{~m}$ is also dominated by the presence of this dipole (cyclonic and anticyclonic gyres). The presence of the mesoscale features was corroborated by the results obtained during the Pelagos and CINCS Projects (Theocharis et al., 1999b; Georgopoulos et al., 2000). These gyres persisted there throughout 1994/95, exhibiting some seasonal variations in their intensities, and minor shifts in
Table 1. Heat and buoyancy loss calculated for the buoy site using ECMWF meteorological data

\begin{tabular}{|c|c|c|c|}
\hline \multirow[t]{2}{*}{ Period } & \multicolumn{3}{|c|}{ Net Flux $(q t)$} \\
\hline & $\begin{array}{c}\text { Buoyancy } \\
{\left[\mathrm{m}^{2} / \mathrm{s}^{2}\right]}\end{array}$ & $\begin{array}{c}\text { Integrated } \\
{\left[\mathrm{J} / \mathrm{m}^{2}\right]}\end{array}$ & $\begin{array}{l}\text { Average } \\
{\left[\mathrm{W} / \mathrm{m}^{2}\right]}\end{array}$ \\
\hline Winter $1999 / 2000$ & -0.91 & $-0.15 E+10$ & -204 \\
\hline December 1999 & -0.25 & $-0.43 E+09$ & -162 \\
\hline January 2000 & -0.45 & $-0.77 E+09$ & -292 \\
\hline February 2000 & -0.21 & $-0.35 E+09$ & -153 \\
\hline \multirow[t]{2}{*}{ Period } & \multicolumn{3}{|c|}{ Net Flux $(q t)$} \\
\hline & $\begin{array}{c}\text { Buoyancy } \\
{\left[\mathrm{m}^{2} / \mathrm{s}^{2}\right]}\end{array}$ & $\begin{array}{c}\text { Integrated } \\
{\left[\mathrm{J} / \mathrm{m}^{2}\right]}\end{array}$ & $\begin{array}{l}\text { Average } \\
{\left[\mathrm{W} / \mathrm{m}^{2}\right]}\end{array}$ \\
\hline Winter $2000 / 2001$ & -0.58 & $-0.97 E+09$ & -129 \\
\hline December 2000 & -0.25 & $-0.42 E+09$ & -162 \\
\hline January 2001 & -0.16 & $-0.26 E+09$ & -98 \\
\hline February 2001 & -0.17 & $-0.29 E+09$ & -127 \\
\hline
\end{tabular}

their position (Georgopoulos et al., 2000). Geostrophic analyses indicated that their influence affects the water column down to $400 \mathrm{~m}$.

The Cretan Sea has been characterised as a "heat and salt reservoir" of the Mediterranean due to the relatively high values of temperature and salinity in the entire water column (Hopkins, 1978). The less saline Atlantic Water (AW) enters the Cretan Sea mainly through the Antikithira Strait but occasionally through the Kassos Strait, affecting its salt balance. The presence of the AW is documented in the subsurface layer $(30-200 \mathrm{~m})$ which is characterised by the salinity minimum. In the southwest Cretan Sea, AW is found at approximately $100 \mathrm{~m}$ depth (Lascaratos, 1992). The Asia Minor Current carries the surface saline water of Levantine origin towards the southern Aegean that subsequently extends over large areas of the Cretan Sea, where these waters can be transformed by convective processes into the Cretan Intermediate Water (CIW). The variability in the salinity of the Cretan Sea can be attributed to the extent to which the AW participates in the formation process (Theocharis et al., 1999b). The Transitional Mediterranean Water (TMW) enters the Aegean through the Cretan Arc Straits in two opposite paths filling the entire basin and leading to the formation of a well-defined intermediate "minimum temperature and salinity" layer (Theocharis et al., 1999b). Towards the deep and bottom layers of the Eastern Mediterranean, the TMW seems to be related to the Cretan Deep Water (CDW) outflow.

In early 1990s the structure of the Cretan Sea water column changed as exceptionally dense, salty water of local origin started to fill the deep Cretan Basin and overflowed the sills of the Cretan Arc straits. This drastic change and contribution of dense water continued for a period of 7-8 years. Due to its high density $\left(\sigma_{\theta}>29.35\right)$, the Cretan Deep Water (CDW) continues to sink, filling the deepest parts of the Levantine and Ionian basins, uplifting the previous deep and 


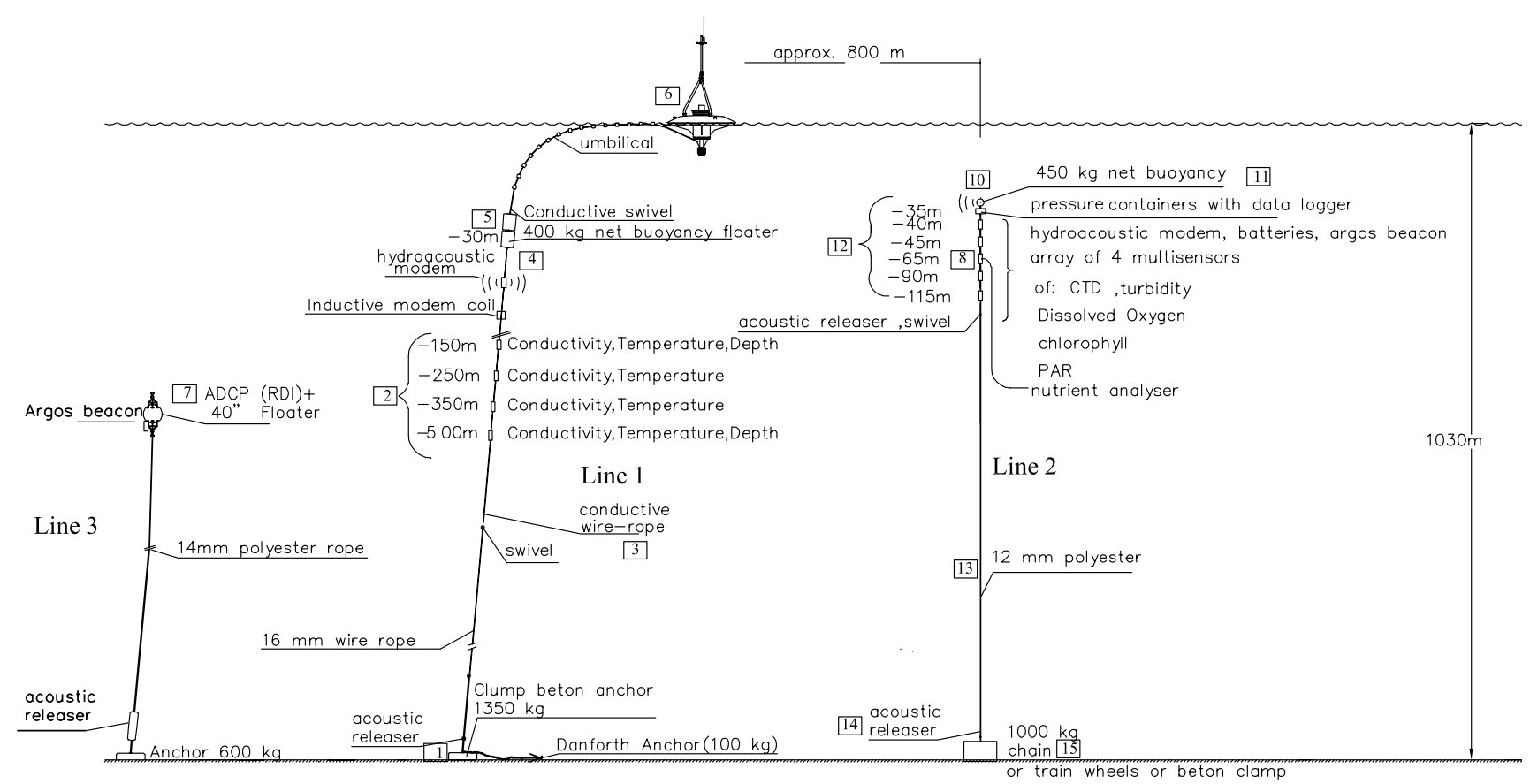

Fig. 2. M3A mooring design.

bottom water, which were of Adriatic origin (Schlitzer et al., 1991; Malanotte-Rizzoli et al., 1996; Roether et al., 1996). So the CDW made a considerable contribution to the formation of the new warmer, saltier and denser deep water observed in the Eastern Mediterranean that has displaced the Eastern Mediterranean Deep Water (EMDW), and the Cretan Sea appears to be a very important (or unique) source of the new type of EMDW.

In this paper we present an extended analysis of one year of data from the M3A site, aimed at determining the subinertial variability of physical properties of the water column, currents and their relationship with possible forcing mechanisms, such as wind and heat fluxes. It is divided into five sections: (1) Introduction; (2) Methods and data; (3) Results: (a) description of physical parameters; (b) description of horizontal and vertical current components; (c) application of the Empirical Orthogonal Function method; (4) Analysis and discussion and (5) Concluding Remarks.

\section{Methods and data}

Time series of current and physical state variables were collected almost continuously at M3A buoy site ( $20 \mathrm{~nm}$ north of Crete) since March 2000 at different levels. The buoy is located at $35^{\circ} 40^{\prime} \mathrm{N} 25^{\circ} \mathrm{E}$ at a water depth of $1030 \mathrm{~m}$ (Fig. 1). The configuration of the M3A system consists of three separate mooring lines: line 1 is dedicated to measurements of physical parameters from $150 \mathrm{~m}$ down to $500 \mathrm{~m}$, while the second one is dedicated to the biological, chemical and physical measurements within the upper $100 \mathrm{~m}$. A third line contains an upward looking Acoustic Doppler Current Profiler -
ADCP (Fig. 2). Nittis et al. (2003) give a detailed description of the system.

Physical parameters (pressure, temperature and conductivity) were measured at nominal depths of 45, 65, 90, 115, 150, 250, 350 and $500 \mathrm{~m}$. On the other side, chemical and biological parameters as chlorophyll- $a$, dissolved oxygen, Photosynthetically Active Radiation (PAR) were measured in the upper $115 \mathrm{~m}$, which coincide with the euphotic zone for this type of oligotrophic area (Nittis et al., 2003, Table 1). Nitrates were sampled only at the level of $45 \mathrm{~m}$. Air-sea interaction parameters like air temperature, humidity, wind speed, gust and direction and air pressure were supposed to be measured, in order to calculate the atmospheric forcing function used to drive the basin-wide and regional models, but, unfortunately, only 4 months of continuous measurements were completed when the surface buoy detached itself and drifted away from the rest of the system. Sampling of all physical and biochemical parameters was carried out every three hours for the period between 4 March 2000 and 28 February 2001.

The quality of M3A data was controlled against in situ measurements performed by R/V Filia during the regular maintenance cruises (15 May 2000, 31 July 2000, 28 October 2000). During each visit, CTD casts were carried out for the whole water column using a SBE-25 probe, while water samples were acquired at the depths where the M3A sensors were located. The water samples were used for laboratory analysis for dissolved oxygen, chlorophyll- $a$ and nutrients, as well as for reference salinity measurements with a standard salinometer. The calibration procedure (Nittis et al., 2003) resulted in a repeating correction of chl- $a$ and dis- 
solved oxygen measurements during each maintenance visit, while no correction was found to be necessary for the rest of the M3A measurements, including the physical parameters used in this paper.

Current measurements are obtained at every $10 \mathrm{~m}$ from an upward looking $75 \mathrm{kHz}$ ADCP every half an hour. For the present analysis, the data were sub-sampled every $6 \mathrm{~h}$ at 11 levels, unequally spaced in the range between $45 \mathrm{~m}$ and $445 \mathrm{~m}$, mainly at depths where physical and biochemical parameters were sampled. The time series were divided into two periods: (a) from 4 March 2000 to 1 July 2000 and (b) from 6 September 2000 to 28 February 2001. The ADCP data will be referred to a Cartesian coordinate system $(x, y, z)$ with $x$ positive eastward, $y$ positive northward and $z$ positive upwards. The eastward, northward and vertical velocities will be denoted by $u, v$ and $w$, respectively. In general, the percentage of good data stored during the whole studied period was approximated by $90-100 \%$. This percentage decreases very significantly towards the surface, especially in the upper two cells. Unfortunately, the instrument stopped measuring on 2 July without any apparent reason, creating an appreciable gap in the time series, since a new deployment was performed only at the beginning of September 2000, thus collecting the data until the end of February 2001. An analysis of the vertical component of the velocity, defined as the average of the vertical projection of all four beams, was also done. The vertical velocity time series were low-pass filtered in order to eliminate high frequency variability due to daily migration of the zooplankton.

The Empirical Orthogonal Function analysis (EOF) has been applied to temperature and horizontal current components. The temperature data set was divided into the same periods as the ADCP time series, in order to determine the possible links between this parameter and currents. The daily variability, both from the temperature and horizontal current time series has been filtered out. The data were organized into two sets: (a) temperature at seven levels $(45 \mathrm{~m}$, $65 \mathrm{~m}, 115 \mathrm{~m}, 150 \mathrm{~m}, 250 \mathrm{~m}, 350 \mathrm{~m}$ and $445 \mathrm{~m}$ ) and (b) ADCP data containing meridional $(v)$ component (north-south) and zonal $(u)$ component (east-west) at 11 levels. In both cases, since the first two EOF modes represent about $95 \%$ of the contribution, higher modes will not be considered.

\section{Results}

\subsection{Description of physical parameters}

\subsubsection{Temperature}

The time-depth diagram of temperature for one-year measurements between March 2000 and February 2001 is shown in Fig. 3, from a nominal depth of $45 \mathrm{~m}$ down to $500 \mathrm{~m}$, using 7 time series data. The upper layer vertical scale between $45 \mathrm{~m}$ and $150 \mathrm{~m}$ has been stretched with respect to the deeper layer, in order to put in evidence some features occurring within it. During March and at the beginning of April (Julian

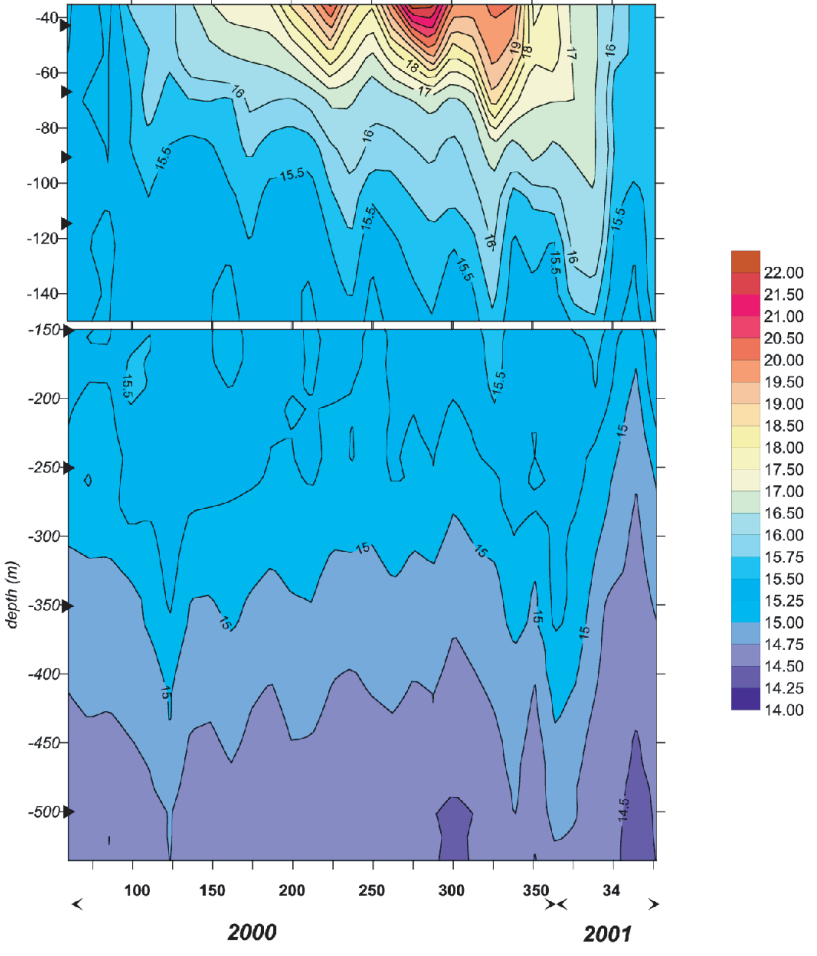

Fig. 3. Time/depth diagram of the temperature (deg. C) for one year of measurements. Position of the instrument is shown by a triangle.

days 65-95 hereafter J.D.), the temperature is homogeneous along the whole water column and varies between $14.5^{\circ} \mathrm{C}$ $(500 \mathrm{~m})$ and $15.5^{\circ} \mathrm{C}(150 \mathrm{~m})$. The beginning of the seawater heating leads to the onset of the seasonal thermocline and the stratification of the upper layer in a rather short time. From mid-May (J.D. 135) onwards the thermocline is set up and occupies a layer down to $75 \mathrm{~m}$ having a Brünt-Väisälä frequency of $N=5.142 \times 10^{-3} \mathrm{cph}$. The continuous heating resulted in a strong stratification with a $N=7.02 \times 10^{-3} \mathrm{cph}$ in June and $7.674 \times 10^{-3} \mathrm{cph}$ in July, indicating the high stability of the water column. In July, the temperature above $50 \mathrm{~m}$ reached $20^{\circ} \mathrm{C}$ and remained around this value until the end of October (J.D. $\approx 300$ ). At the beginning of August the water column is very stable showing a Brünt-Väisälä frequency of $0.0106 \mathrm{cph}$. The temperature field in the thermocline layer shows high-frequency oscillations at a time scale of 20 days, which may be associated with the presence of cyclonic and anticyclonic eddies in the mooring area.

The heating continued to influence the upper layer, maintaining it strongly stratified until the beginning of winter (December-J.D. 325) when the stratification of the layer broke down and the isotherm of $15.5^{\circ} \mathrm{C}$ outcropped. The water column at the beginning of the measurements, i.e. March 2000 (J.D. $=60$ ) is mixed down to $250 \mathrm{~m}$ or more, while the mixing reaches only $100 \mathrm{~m}$ during February 2001. From a heat- and buoyancy loss point of view it is evidenced that winter 99/00 was stronger than winter 00/01 (Fig. 4 and Table 1). The integrated heat flux and buoyancy loss is about 
100

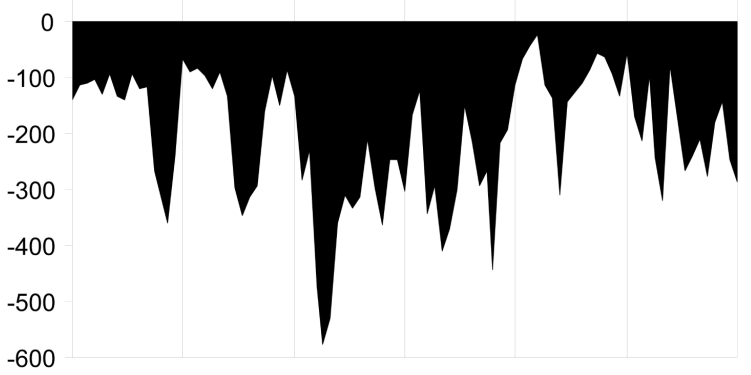

01/12/1999 16/12/1999 31/12/1999 15/01/2000 30/01/2000 14/02/2000 29/02/2000

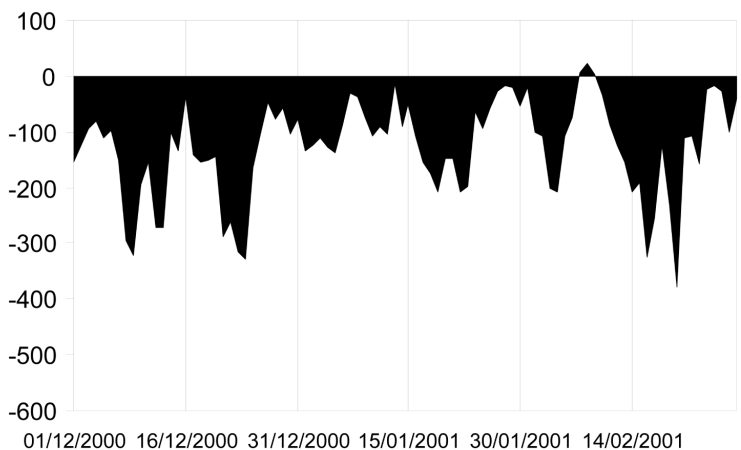

Fig. 4. Low-pass daily heat fluxes calculated from ECMWF data for the M3A buoy site for winters $99 / 00$ and $00 / 01$.

$-0.159 \times 10^{-10} \mathrm{~J} / \mathrm{m}^{-2}$ and $0.941 \mathrm{~m}^{2} / \mathrm{s}^{2}$, respectively, during the first winter, detecting a maximum heat loss event of $600 \mathrm{~W} / \mathrm{m}^{2}$. On the other hand, during the following winter, values of $-0.976 \times 10^{-9} \mathrm{~J} / \mathrm{m}^{-2}$ and $-0.584 \mathrm{~m}^{2} / \mathrm{s}^{2}$ for heat and buoyancy loss are obtained and no events stronger than $400 \mathrm{~W} / \mathrm{m}^{2}$ occurred; consequently, much shallower convection took place.

As far as the intermediate layer is concerned, it also shows oscillations of the order of 10 days during spring, summer and autumn (from J.D. 125 to J.D. 325) not being correlated with the upper thermocline variability. In addition, this layer seems to be influenced by a basin-wide cyclonic circulation generating seasonal upwelling on which the high-frequency oscillations are superimposed. As it will be seen later, from the vertical velocities analysis, the downward velocities, in most cases, coincide with the presence of the anticyclonic gyre in the mooring area and vice versa, which is in agreement with the patterns seen in the temperature field. Two intense downwelling events occurred during the year of measurements; (J.D. 125 and J.D. 360), which were felt over the entire intermediate layer. Moreover, the upwelling, which took place at the beginning of the year 2001, was detected carrying cold waters up to the surface along the entire water column from 0 to $500 \mathrm{~m}$.

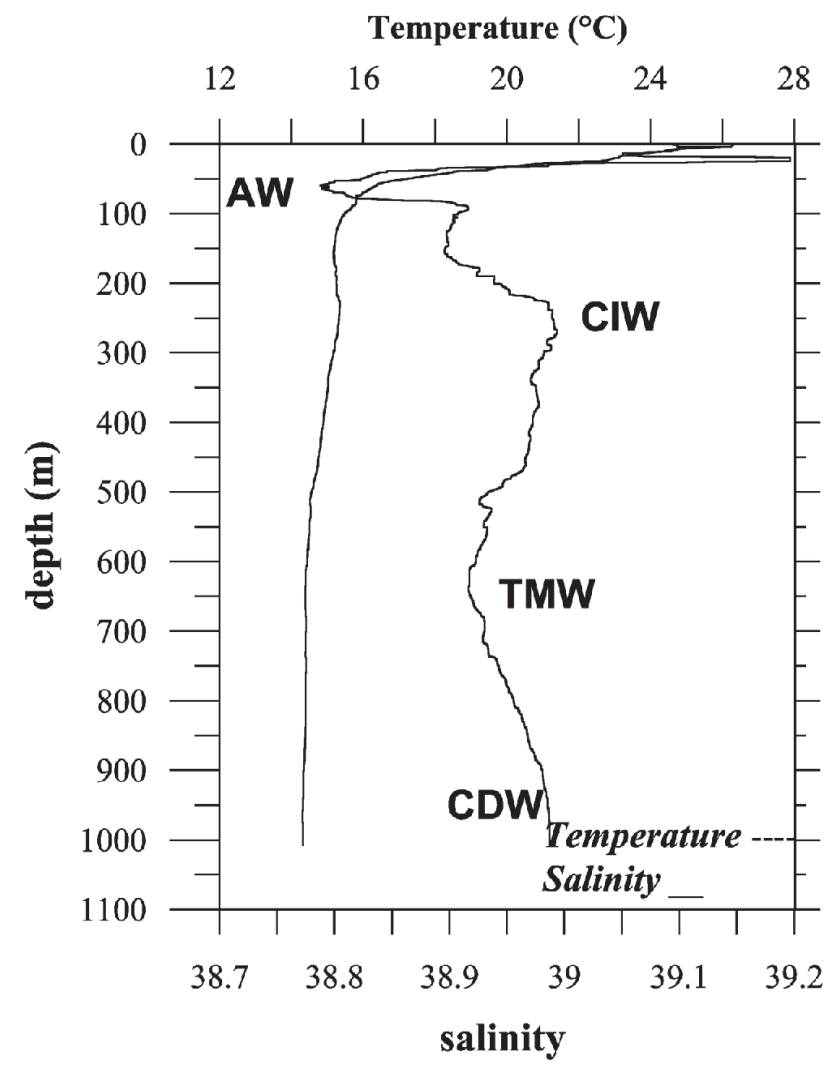

Fig. 5. Temperature and salinity profiles measured in situ during the maintenance cruise of 1 August 2000.

\subsubsection{Salinity}

The Cretan Sea is an area with a complex salinity structure, since at least four distinct water masses can be identified throughout the year (Theocharis et al., 1999b). In Fig. 5, an example of salinity and temperature profiles measured during the mooring maintenance campaign is present. In this salinity profile the four water masses present in the area are evident. The so-called Atlantic Water (AW), i.e. the low-salinity water that enters the Mediterranean Sea through the Gibraltar Strait, to compensate for the negative freshwater budget of the basin (Wüst 1961), influences the upper $100 \mathrm{~m}$. When the salinity of the upper $50 \mathrm{~m}$ is increased during summer, due to excessive evaporation, the AW creates a characteristic subsurface salinity minimum (Lacombe and Tchernia. 1960). At intermediate depths (200-500 m) warm and saline Cretan Intermediate Water (CIW) is present with characteristics similar to the Levantine Intermediate Water $(\mathrm{LIW})\left(\theta=14.5-15.5^{\circ} \mathrm{C}, S=38.95-39.10\right)$ that occupies the intermediate layers of the Mediterranean Sea. The salinity increases in the deeper layers (below 800) where the warm $\left(\theta>13.9^{\circ} \mathrm{C}\right)$ but saline $(S>39.0)$ and hence dense $\left(\sigma_{\theta} 29.10\right.$ - 29.40) Cretan Deep Water (CDW) is found. The increased volume and density of this water mass in the period 1987-1993 (Theocharis et al., 1999a), and its outflow through the straits of the Cretan Arc, induced 


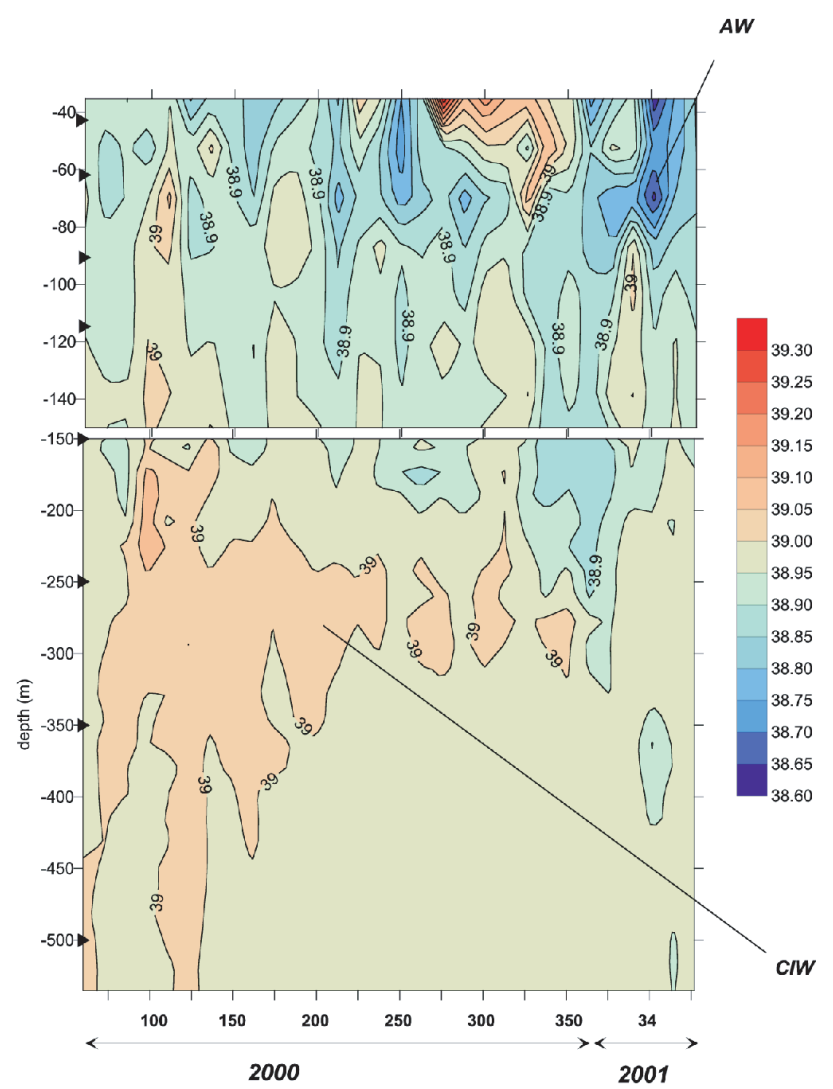

Fig. 6. Time/depth diagram of the salinity for one year of measurements. Position of the instrument is shown by a triangle.

important changes in the water mass structure of the whole Mediterranean Sea, an event usually referred to as the Eastern Mediterranean Transient (Roether et al., 1996). Finally, in between the CIW and CWD, at $600 \mathrm{~m}$ depth, TMW is observed and characterised by low salinity and temperature. This water entered the Cretan Sea after 1993 to compensate for the increased outflow of dense water from intermediate and deep layers.

The time/depth salinity diagram is characterised by a very high variability (Fig. 6). The temporal variability of the salinity structure is intense both at the synoptic and the seasonal time scales. At the synoptic time scale, we observe episodes of horizontal and vertical advective events that create pulses of fresh or saline water mainly at surface and at the CIW upper boundary $(150 \mathrm{~m})$. At longer time scales, we observe a presence of an important volume of the CIW with salinity values above 39.00 during March/April 2000 (J.D. 60-120), which gradually mixes, disappearing by the end of the year. One year later, the thickness of this layer diminished and the maximum salinity dropped below 39.00. This water mass is not locally produced, since its appearance cannot be attributed to any dense water formation event in the area and thus, it should be advected from another part of the Cretan Sea.

At seasonal time scales, we observe the development of
Table 2. Statistical parameters of ADCP measurements

\begin{tabular}{|c|c|c|c|c|}
\hline \multicolumn{5}{|c|}{$\begin{array}{c}\text { Period: } \\
04 \text { Mar } 2000 \text { - } 01 \text { Jul 2000; J.D. } 64 \text { - J.D. } 183\end{array}$} \\
\hline \multirow[t]{2}{*}{ Depth (m) } & \multicolumn{3}{|c|}{ Current speed $(\mathrm{cm} / \mathrm{s})$} & \multirow{2}{*}{$\begin{array}{c}\text { Mean } \\
\text { Direction }\end{array}$} \\
\hline & Max & Mean & Std dev & \\
\hline 47 & 52 & 14.6 & 8.4 & 175 \\
\hline 67 & 47 & 14.1 & 7.9 & 175 \\
\hline 97 & 44 & 13.2 & 7.3 & 174 \\
\hline 117 & 43 & 12.8 & 7.0 & 174 \\
\hline 156 & 44 & 12.2 & 6.5 & 174 \\
\hline 256 & 37 & 10.5 & 5.0 & 172 \\
\hline 327 & 25 & 9.0 & 4.2 & 171 \\
\hline 356 & 28 & 8.4 & 4.0 & 170 \\
\hline 377 & 27 & 7.9 & 3.8 & 168 \\
\hline 407 & 20 & 7.2 & 3.4 & 164 \\
\hline 446 & 17 & 6.2 & 2.9 & 156 \\
\hline \multicolumn{5}{|c|}{$\begin{array}{c}\text { Period: } \\
04 \text { Sep } 2000 \text { - } 01 \text { Mar 2001; J.D. } 250 \text { - J.D. } 60\end{array}$} \\
\hline \multirow[t]{2}{*}{ Depth (m) } & \multicolumn{3}{|c|}{ Current speed $(\mathrm{cm} / \mathrm{s})$} & Mean \\
\hline & Max & Mean & Std dev & Direction \\
\hline 47 & 73 & 19.4 & 9.8 & 168 \\
\hline 67 & 83 & 17.6 & 9.1 & 166 \\
\hline 97 & 91 & 17.4 & 10.0 & 167 \\
\hline 117 & 96 & 17.5 & 11.1 & 168 \\
\hline 156 & 144 & 17.6 & 12.7 & 168 \\
\hline 256 & 86 & 13.4 & 9.1 & 162 \\
\hline 327 & 35 & 10.0 & 6.1 & 154 \\
\hline 356 & 28 & 9.1 & 5.2 & 148 \\
\hline 377 & 25 & 8.5 & 4.7 & 145 \\
\hline 407 & 22 & 7.8 & 4.0 & 140 \\
\hline 446 & 19 & 7.3 & 3.6 & 134 \\
\hline
\end{tabular}

the surface saline layer during the summer period following the formation of the seasonal thermocline. Although we only observe the lower part of this layer (our first sensor is at $45 \mathrm{~m}$ depth), maximum salinity values exceed 39.3 . During September and October, when the thermocline is gradually destroyed, this surface saline water intrudes into deeper layers, down to $80 \mathrm{~m}$ depth.

3.2 Analysis of the horizontal and vertical current components

Time series of 6-hourly sub-sampled horizontal current vectors for 8 chosen levels for the first period are shown in Fig. 7. They are characterised by the presence of a seasonal signal, where winter currents are strong and decrease in intensity towards the summer. Besides, they are characterised by relatively high stability of the onshore (southward) direction. The currents down to $250 \mathrm{~m}$ were quite strong (up to $50 \mathrm{~cm} / \mathrm{s}$ ), with short periods of reversals (towards north) during winter, while in deeper layers the magnitude of the velocity decreases (less than $25 \mathrm{~cm} / \mathrm{s}$ ). There were few episodes at 


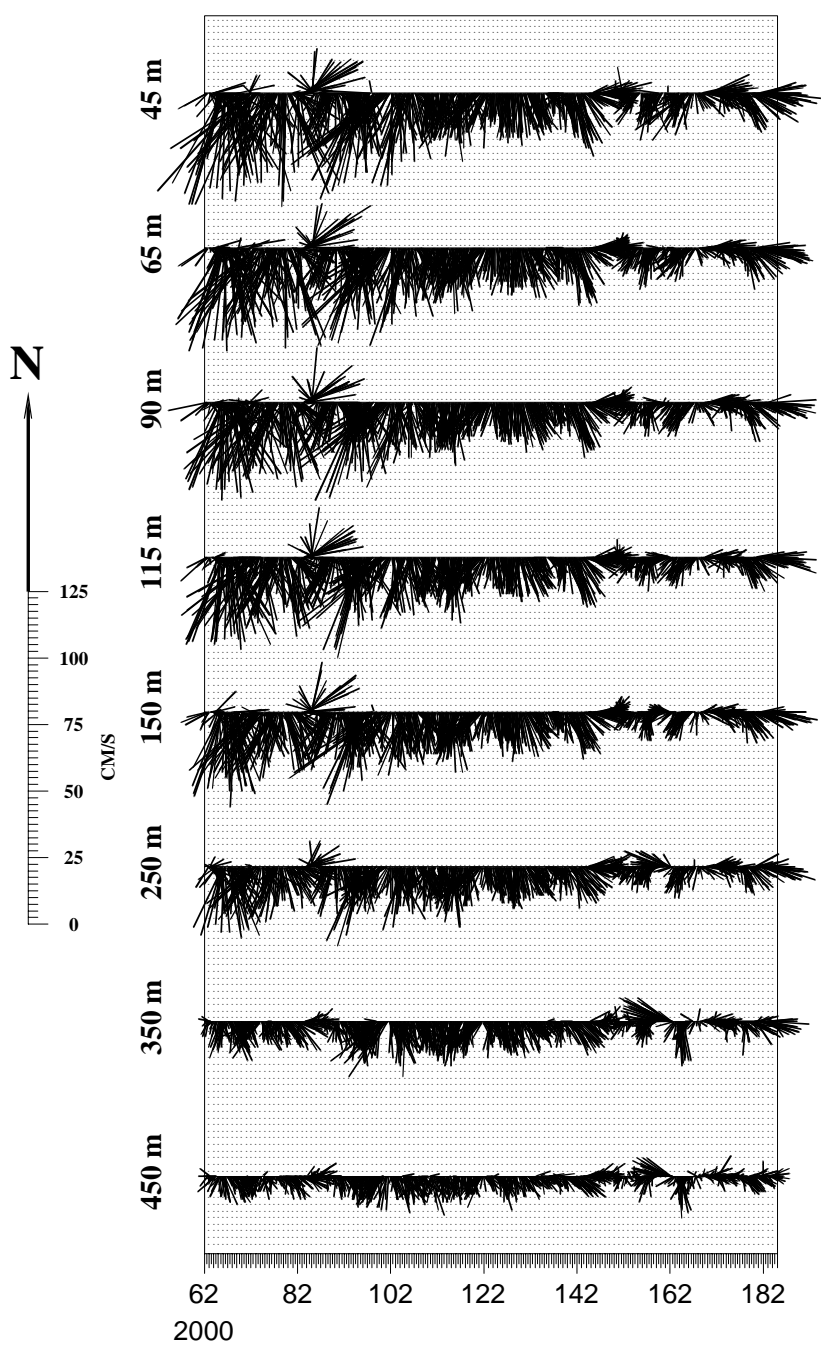

Fig. 7. Stick diagram of ADCP currents at different levels for the first period (04 March 2000-01 July 2000; J.D. 64 - J.D. 183).

different time scales, where the flow gradually or suddenly changed direction during the first period of measurements: a very sharp reversal occurred by the end of March with a duration of a few days; some others, less intense but longer, were identified at the end of May up to June (J.D. from 146-152).

By mid-April the current velocity field started to decrease with values between $20-30 \mathrm{~cm} / \mathrm{s}$ but maintaining a southward direction, possibly indicating a displacement of the dipole westward or eastward so that the center of either the cyclone or the anticyclone came close to the mooring site. Another possible explanation can be sought in a general weakening of the circulation associated to dipole. During May-June the current was less intense and less stable than in early spring, in net disagreement with the characteristics of 94/95 (see Georgopoulos et al., 2000 - CINCS Project). The complete statistics for the whole year of measurements at a selected depth is shown in Table 2. The tendency of the mean current speed and variability is to decrease with depth. A large part of current variability appears to be depth-independent or

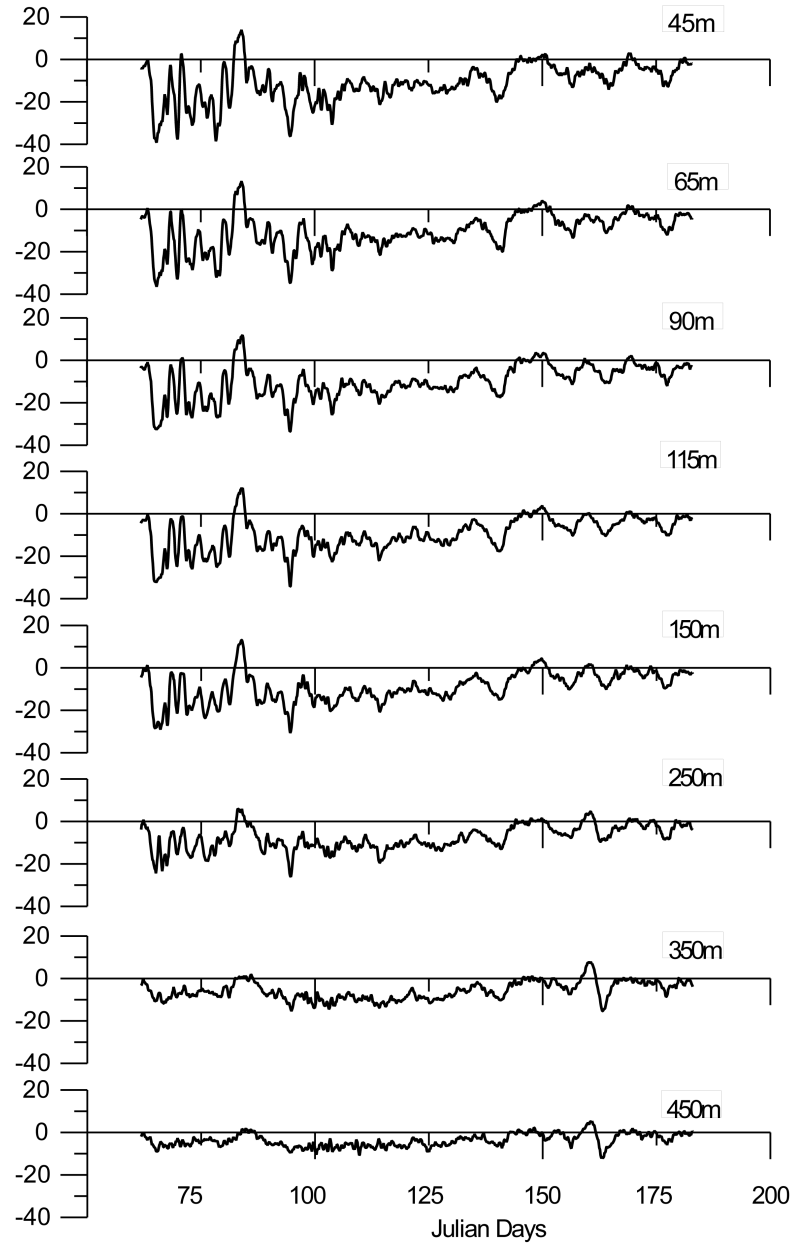

Fig. 8. Meridional velocities $(\mathrm{cm} / \mathrm{s})$ at different levels for the first period (04 March 2000-01 July 2000; J.D. 64 - J.D. 183).

barotropic-like down to $250 \mathrm{~m}$ with a constant vertical shear. This feature can be observed from the $v$-component time series at different levels for the first period shown in Fig. 8. This characteristic is confirmed by the results of the empirical orthogonal function analysis, which will be discussed in the next section.

The second period of measurements (Fig. 9) shows stronger currents in the upper $250 \mathrm{~m}$ having more energetic variability than in the first part of the year. On the contrary, the velocities of the layer below remain within the range measured during the summer. From the current velocity variability at different depths (Table 2), an increase in speed variation from the upper layer down to approximately $150 \mathrm{~m}$ can be seen, with mean values around $17.5 \mathrm{~cm} / \mathrm{s}$ and the standard deviation (12.7) is found. At the base of this layer a maximum peak speed $(144 \mathrm{~cm} / \mathrm{s})$ was measured. Beneath this layer, the current speed and standard deviation decrease towards deeper layers, with a minimum found at the last cell of measurements ( $445 \mathrm{~m}$ ). From September up to December 2000 the area was dominated by a flow regime in a S-SE direction, with sporadic reversal of the current, indicating the 


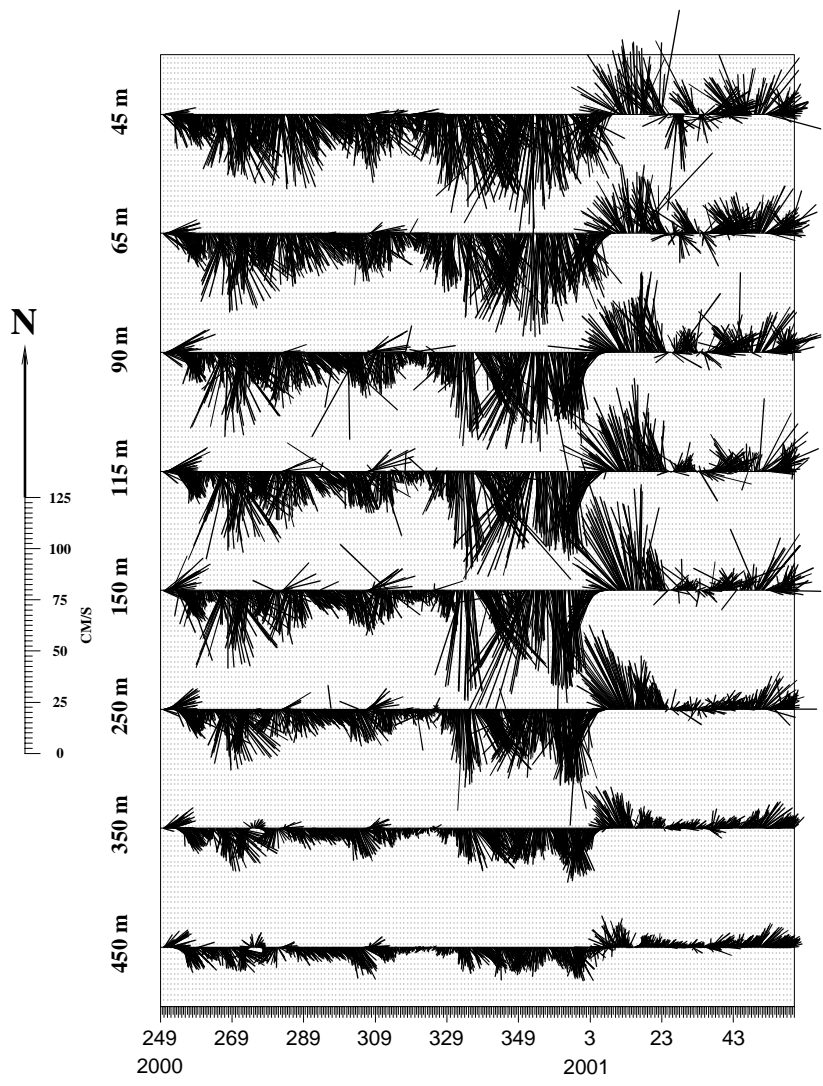

Fig. 9. Stick diagram of ADCP currents at different levels for the second period (06 September 2000 - 01 March 2001; J.D. 250 J.D. 60).

displacement of the cyclone-anticyclone system. By the end of November, the flow starts to increase continuously, reaching its maximum by mid-December when it suddenly started to decrease (probably due to the displacement of the center of one of the gyres). These velocities seem to be vertically coherent over at least $300 \mathrm{~m}$, certainly due to the influence of the above-mentioned dipole system. The flow in the intermediate layer was about half or one-third of the upper one. At the beginning of January 2001, a sharp reversal, with currents flowing in a NW-N direction, occurred and remained for the rest of the recording period, with some sporadic southward flowing episodes. Northward currents coincide with the vertical homogenization of the water column.

The analysis of vertical velocities (positive values indicate an upward movement) indicates a varying behaviour along the whole water column (Fig. 10) during both period of measurements, showing high-frequency variations mainly in the layer between $150 \mathrm{~m}$ and $250 \mathrm{~m}$. Generally, the vertical velocities are characterised by high-frequency oscillations $(24 \mathrm{~h})$, which might not represent real water motion, but the vertical scatterrers' migration through the water column. Such scatterrers could be zooplankton, since it migrates upward after sunset and downward after sunrise. An indication of similar effects was reported by Schott and Leaman (1991), who analyzed ADCP measurements in the Gulf of
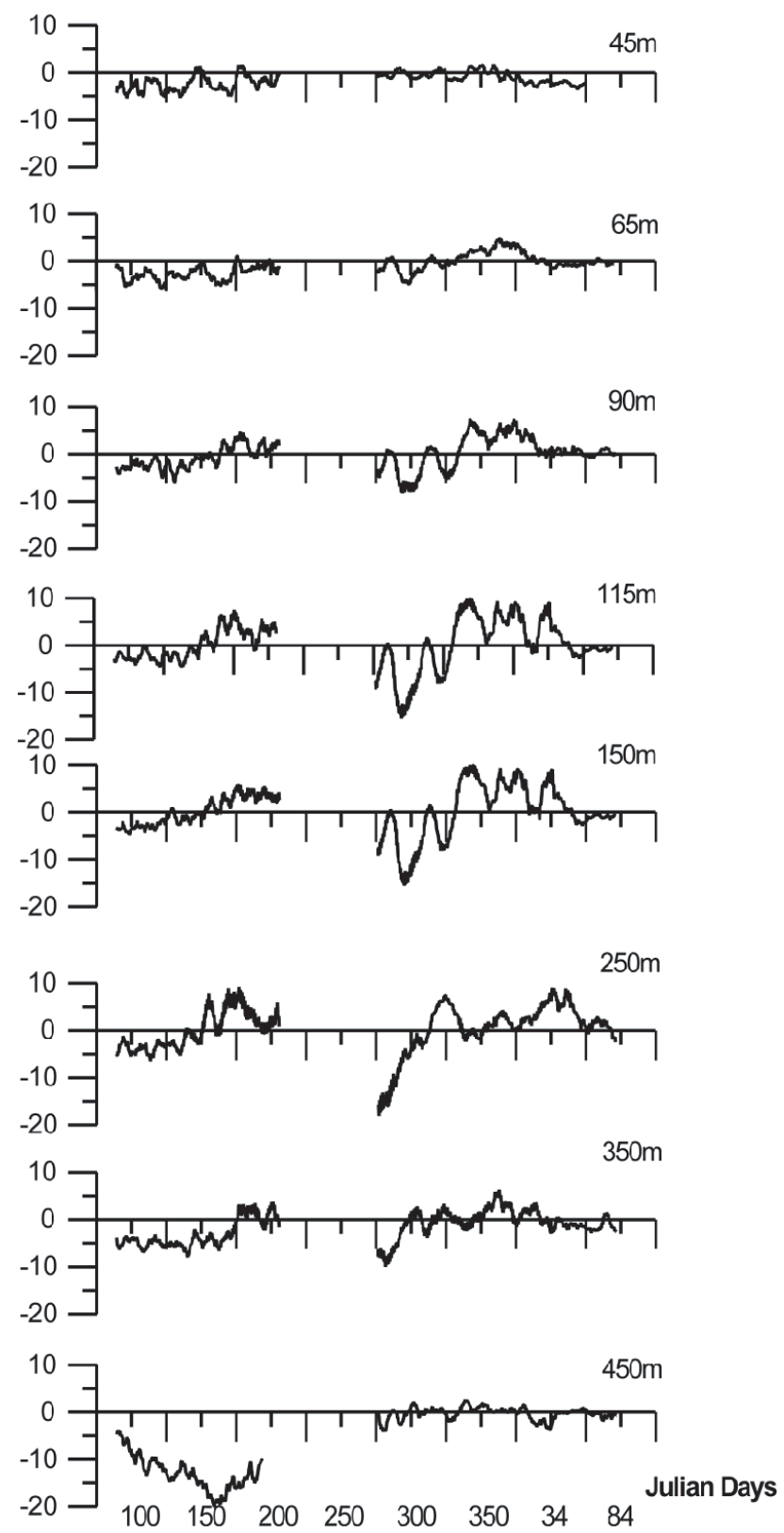

Fig. 10. Vertical velocities $(\mathrm{mm} / \mathrm{s})$ at different levels recorded by the ADCP for the whole period of measurements (04 March $2000-$ 01 March 2001; J.D. 64 - J.D. 60).

Lions. During the first period, the velocities at $40 \mathrm{~m}$ are the least energetic, increasing in magnitude in the deeper layers. The time series at $65 \mathrm{~m}$ shows that the vertical velocities vary from $-10 \mathrm{~mm} / \mathrm{s}$ to $+8 \mathrm{~mm} / \mathrm{s}$, being mainly negative, coinciding with the onset and deepening of the thermocline. The layer between $90 \mathrm{~m}$ and $350 \mathrm{~m}$ is more energetic than the previous one, becoming less and less negative (downward motion) from late winter to early summer. The velocities at $450 \mathrm{~m}$, contrary to what was seen in the above layer, show very strong downward motion, occasionally reaching $-20 \mathrm{~mm} / \mathrm{s}$. The second period shows quite a different trend of the velocity behaviour. As during the first 
Table 3. EOF eigenvectors and total variance explained for the $u$ and $v$ current components during the first phase (04 Mar $2000-01 \mathrm{Jul}$ 2000; J.D. 64 - J.D. 183)

\begin{tabular}{|c|c|c|c|c|c|c|c|c|c|c|c|}
\hline \multicolumn{12}{|c|}{$u$-component } \\
\hline \multicolumn{5}{|c|}{ Eigenvalue mode 1: 9.61} & \multicolumn{7}{|c|}{ Contribution mode 1: $87.4 \%$} \\
\hline \multicolumn{5}{|c|}{ Eigenvalue mode $2: 1.16$} & \multicolumn{7}{|c|}{ Contribution mode $2: 10.5 \%$} \\
\hline Depth (m) & 47 & 67 & 97 & 117 & 157 & 257 & 327 & 357 & 377 & 407 & 447 \\
\hline Mode 1 & 0.290 & 0.297 & 0.304 & 0.308 & 0.309 & 0.317 & 0.311 & 0.305 & 0.300 & 0.294 & 0.280 \\
\hline Mode 2 & -0.371 & -0.346 & -0.302 & -0.265 & -0.227 & -0.041 & 0.198 & 0.278 & 0.321 & 0.361 & 0.422 \\
\hline \multicolumn{12}{|c|}{$v$-component } \\
\hline \multicolumn{5}{|c|}{ Eigenvalue mode 1: 9.57} & \multicolumn{7}{|c|}{ Contribution mode 1: $87.0 \%$} \\
\hline \multicolumn{5}{|c|}{ Eigenvalue mode $2: 1.16$} & \multicolumn{7}{|c|}{ Contribution mode $2: 10.5 \%$} \\
\hline Depth (m) & 47 & 67 & 97 & 117 & 157 & 257 & 327 & 357 & 377 & 407 & 447 \\
\hline Mode 1 & 0.294 & 0.300 & 0.305 & 0.306 & 0.308 & 0.314 & 0.311 & 0.300 & 0.297 & 0.292 & 0.288 \\
\hline Mode 2 & -0.347 & -0.328 & -0.297 & -0.287 & -0.257 & -0.053 & 0.201 & 0.317 & 0.352 & 0.372 & 0.360 \\
\hline
\end{tabular}

Table 4. EOF eigenvectors and total variance explained for the $u$ and $v$ current components during the second phase (06 Sep $2000-01$ Mar 2001; J.D. 250 - J.D. 60)

\begin{tabular}{|c|c|c|c|c|c|c|c|c|c|c|c|}
\hline \multicolumn{12}{|c|}{$u$-component } \\
\hline \multicolumn{5}{|c|}{ Eigenvalue mode 1: 9.56} & \multicolumn{7}{|c|}{ Contribution mode 1: $86.9 \%$} \\
\hline \multicolumn{5}{|c|}{ Eigenvalue mode 2: 0.978} & \multicolumn{7}{|c|}{ Contribution mode $2: 8.9 \%$} \\
\hline Depth (m) & 47 & 67 & 97 & 117 & 157 & 257 & 327 & 357 & 377 & 407 & 447 \\
\hline Mode 1 & 0.251 & 0.278 & 0.307 & 0.309 & 0.310 & 0.315 & 0.315 & 0.313 & 0.311 & 0.306 & 0.295 \\
\hline Mode 2 & -0.371 & -0.346 & -0.302 & -0.265 & -0.227 & -0.041 & 0.198 & 0.278 & 0.321 & 0.361 & 0.422 \\
\hline \multicolumn{12}{|c|}{$v$-component } \\
\hline \multirow{2}{*}{\multicolumn{5}{|c|}{$\begin{array}{l}\text { Eigenvalue mode } 1: 10.2 \\
\text { Eigenvalue mode } 2: 0.515\end{array}$}} & \multirow{2}{*}{\multicolumn{7}{|c|}{$\begin{array}{l}\text { Contribution mode } 1: 92.4 \% \\
\text { Contribution mode } 2: 4.7 \%\end{array}$}} \\
\hline & & & & & & & & & & & \\
\hline Depth (m) & 47 & 67 & 97 & 117 & 157 & 257 & 327 & 357 & 377 & 407 & 447 \\
\hline Mode 1 & 0.283 & 0.295 & 0.305 & 0.306 & 0.301 & 0.306 & 0.308 & 0.307 & 0.305 & 0.301 & 0.297 \\
\hline Mode 2 & -0.507 & -0.412 & -0.248 & -0.209 & -0.171 & 0.046 & 0.216 & 0.267 & 0.312 & 0.335 & 0.329 \\
\hline
\end{tabular}

period, no significant vertical motion characterises the layer between $40-65 \mathrm{~m}$ for the whole period, contrary to the underlying one (between $90 \mathrm{~m}$ and $250 \mathrm{~m}$ ) that seems to be the most energetic, showing high variability and velocity oscillations between $-25 \mathrm{~mm} / \mathrm{s}$ and $20 \mathrm{~mm} / \mathrm{s}$, especially in the period September-December 2000 (J.D. 250-350). In this layer, the time series showed to be highly correlated. During September/October (J.D. 250-300), the vertical velocities were mainly negative, indicating the presence of a downward motion. By the end of October (J.D. 300) the velocities changed sign, indicating an upward motion, which continued until the end of the year. From the beginning of the year 2001 the velocities decrease sharply, becoming almost negligible. The deepest measurement depth $(450 \mathrm{~m})$, contrary to what was seen in the first period, did not show any significant feature, and the vertical velocities were very weak. Some of the features highlighted by the vertical movement could be associated with the ones seen in the temperature field. In fact, oscillations present in the temperature field of the order of a month, can be associated with the ones observed in the vertical currents measured during September/October (J.D. 250 300 ), especially those observed in the layer between $90 \mathrm{~m}$ and $250 \mathrm{~m}$.

\subsection{Application of the Empirical Orthogonal Function (EOF) method to physical parameters}

We have investigated the structure of spatial and temporal variability using Empirical Orthogonal Function analysis (EOF), applied separately to the $u$ and $v$ components of the current and to the temperature data along the water column down to 450 m (Preisendorfer, 1988; Kundu et al., 1975; Kundu and Allen, 1976). As we mentioned in Sect. 2, the 

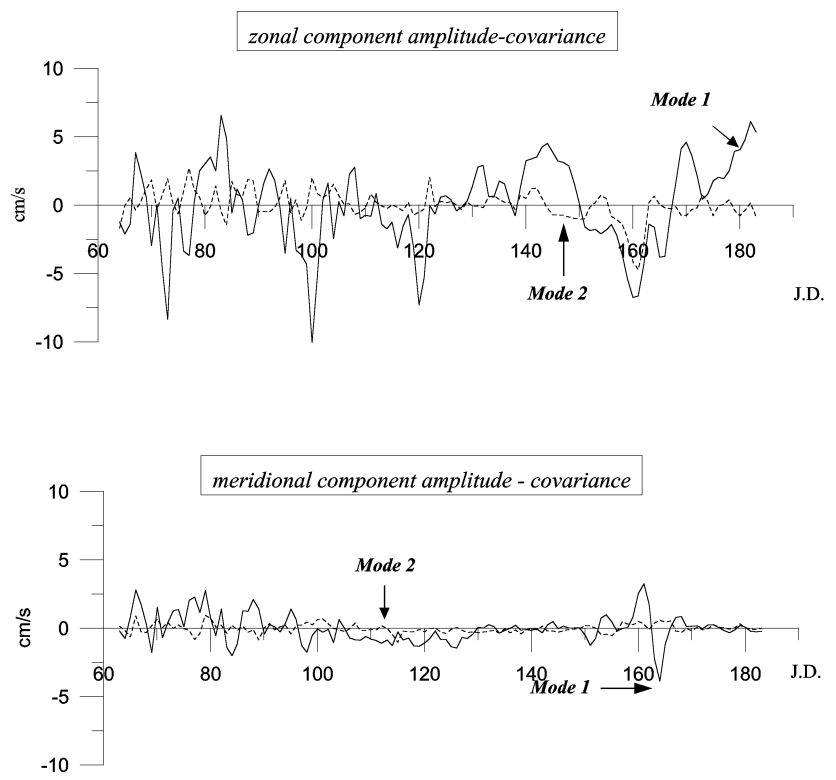

Fig. 11. Zonal and meridional component amplitude time series for the first period (04 March 2000 - 01 July 2000; J.D. 64 - J.D. 183).

EOF analysis was applied to the data set divided into two periods: 04 March 2000 - 01 July 2000 and 06 September 2000 - 28 February 2001, corresponding to the period of the ADCP measurements, in order to correlate both amplitude series. For the analysis we have used the covariance matrix obtained from the low-pass filtered (moving average) time series, in order to determine eigenvalues and eigenvectors.

\subsubsection{Currents}

In general, eigenvectors, eigenvalues and time amplitude variation series obtained from the application of the EOF analysis show that most of the variance is contained in the first two modes resembling the barotropic and the first baroclinic mode. During the first phase (Fig. 11 and Table 3), about $98 \%$ of the variance is accounted for by the first two eigenfunctions, with the first one accounting for more than $87 \%$. The first mode is fairly barotropic and the second mode of both current components (10\%) exerts baroclinic-like variability: the upper layer (down to $300 \mathrm{~m}$ ) is out of phase with respect to a lower one. The time amplitude series of the first and second modes from each one of the components suggest that the variability can be associated with the current variations due to the displacements of the mesoscale dipole. This variability coincides with the pattern observed in the temperature field in Fig. 3. Generally, the first mode amplitude time series is characterised by a series of oscillations, varying from +7 to $-7 \mathrm{~cm} / \mathrm{s}$, while the second one is less energetic. During April and part of May 2000 the variability of the meridional component amplitude decreases and is mainly negative, coinciding with the prevalence of the southward flow. The net reversal of the flow, which took place by the end of May and the beginning of June (J.D. 145-155), can be evidenced in the first mode, which means that it is
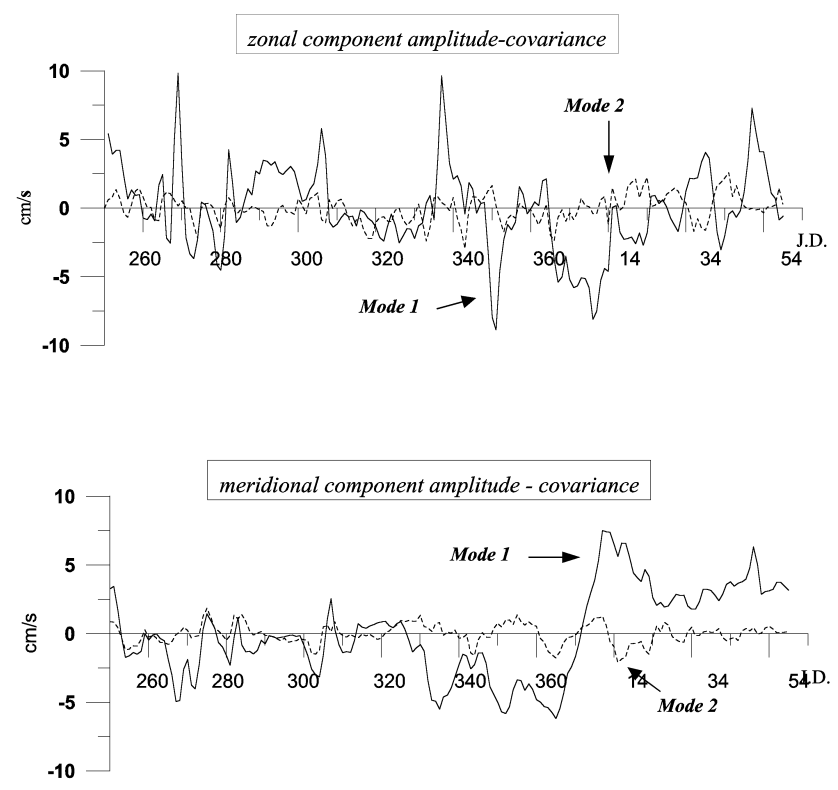

Fig. 12. Zonal and meridional component amplitude time series for the second period (06 September 2000 - 01 March 2001; J.D. 250 - J.D. 60).

a barotropic-like change. For the second period (Fig. 12), the configuration of the first mode of the zonal and meriodional component ( $87 \%$ and $94 \%$, respectively) is associated with the barotropic-like structure, as was the case during the first phase. The second mode resembles the baroclinic mode vertical structure $(8.9 \%$ for the $u$ - and $4.7 \%$ for the $v$ component). A slightly different behaviour of the barocliniclike structure was observed during this period: the dimension of the layer, being out of phase with respect to a deeper one, is thinner. The contribution of the first and second mode of the meridional component is less similar than during the first period. In the $v$-component the contribution of the first mode is more important in the second period than in the first one. The amplitude of the first mode of both components is characterised by stronger high-frequency fluctuations than the second mode. The reversal to a northward flow, from the beginning of the year onwards, is evident in the first mode amplitude time series of the meridional component, as it should be expected.

\subsubsection{Temperature}

For the first period, the principal characteristics of the EOF eigenvectors is the prevailing contribution of the first two modes $(96 \%)$ of the total variance explained (Table 5). The first mode, which accounts for most of the energy (90.3\%), shows the seasonal heating of the water column decreasing sharply from 45 to $60 \mathrm{~m}$. Below this depth, the fluctuations are less significant. The amplitude of the first mode (Fig. 13) is characterised by fluctuations superimposed over a trend, which reproduces the gradual increase of the temperature from late winter to summer. This trend represents a portion of the seasonal variability. The second mode accounts 
Table 5. EOF eigenvectors and total variance explained for the temperature during the first and second phase (04 Mar $2000-01 \mathrm{Jul} 2000$; J.D. 64 - J.D. 183 and (06 Sep 2000 - 01 Mar 2001; J.D. 250 - J.D. 60)

\begin{tabular}{|c|c|c|c|c|c|c|c|}
\hline \multicolumn{8}{|c|}{ Temperature - first phase } \\
\hline \multirow{2}{*}{\multicolumn{3}{|c|}{$\begin{array}{l}\text { Eigenvalue mode } 1: 0.832 \\
\text { Eigenvalue mode } 2: 0.054\end{array}$}} & \multirow{2}{*}{\multicolumn{5}{|c|}{$\begin{array}{l}\text { Contribution mode } 1: 90.3 \% \\
\text { Contribution mode } 2: 5.8 \%\end{array}$}} \\
\hline & & & & & & & \\
\hline Depth & $40 \mathrm{~m}$ & $65 \mathrm{~m}$ & $115 \mathrm{~m}$ & $150 \mathrm{~m}$ & $250 \mathrm{~m}$ & $350 \mathrm{~m}$ & $500 \mathrm{~m}$ \\
\hline Mode 1 & 0.956 & 0.289 & 0.038 & -0.005 & 0.027 & 0.006 & 0.006 \\
\hline Mode 2 & -0.184 & 0.504 & 0.560 & 0.442 & 0.332 & 0.283 & 0.110 \\
\hline \multicolumn{8}{|c|}{ Temperature - second phase } \\
\hline \multirow{2}{*}{\multicolumn{3}{|c|}{$\begin{array}{l}\text { Eigenvalue mode } 1: 0.633 \\
\text { Eigenvalue mode } 2: 0.149\end{array}$}} & \multirow{2}{*}{\multicolumn{5}{|c|}{$\begin{array}{l}\text { Contribution mode } 1: 73.0 \% \\
\text { Contribution mode } 2: 17.2 \%\end{array}$}} \\
\hline & & & & & & & \\
\hline Depth & $65 \mathrm{~m}$ & $90 \mathrm{~m}$ & $115 \mathrm{~m}$ & $150 \mathrm{~m}$ & $250 \mathrm{~m}$ & $350 \mathrm{~m}$ & $500 \mathrm{~m}$ \\
\hline Mode 1 & 0.926 & 0.288 & 0.190 & 0.108 & 0.068 & 0.061 & 0.053 \\
\hline Mode 2 & -0.322 & 0.564 & 0.670 & 0.273 & -0.042 & -0.212 & -0.094 \\
\hline
\end{tabular}

for $5.8 \%$ of the total variance; it is less energetic and can be associated to the variability of the temperature below the thermocline, probably due to the influence of the mesoscale dipole feature.

In the second period as well, the most important features are reflected in the first and the second modes, which account for $90.2 \%$ of the total variability. Contrary to the first period, where most of the variance is distributed between mode 1 and 2 , in the second one, the total variance is more evenly distributed in more modes. It is important to point out that during this period (second phase) the $45 \mathrm{~m}$ time series is missing, where most of the seasonal variability is contained. This fact precludes us from comparing the depthstructure obtained from the EOF analysis of the two periods. Note that the first mode now contributes with $73 \%$ instead of $90.3 \%$; it still contains the seasonal variations of the thermal structure of the water column, principally at $65 \mathrm{~m}$. The temperature amplitude variability of mode 1 is characterised by high-frequency oscillations, especially during the late summer and early autumn. The breakup of the thermocline and the cooling of the water column in winter is associated with the decreasing trend of the amplitude time series. Again, the absence of the 45-m time series prevents us from having a clear picture of these processes. During this period, the slope is negative and the temperature decreases. The second mode contributes with $17.2 \%$ and can be associated with the temperature variations occurring in the layer between $90 \mathrm{~m}$ and $150 \mathrm{~m}$, layers that are out of phase with respect to the rest of the water column.

\section{Analysis and discussion}

Continuous measurements of physical and biochemical parameters in the surface and intermediate layers have permitted us to describe some features of the Cretan Sea. A multiple scale circulation pattern prevails in the region of the Cretan
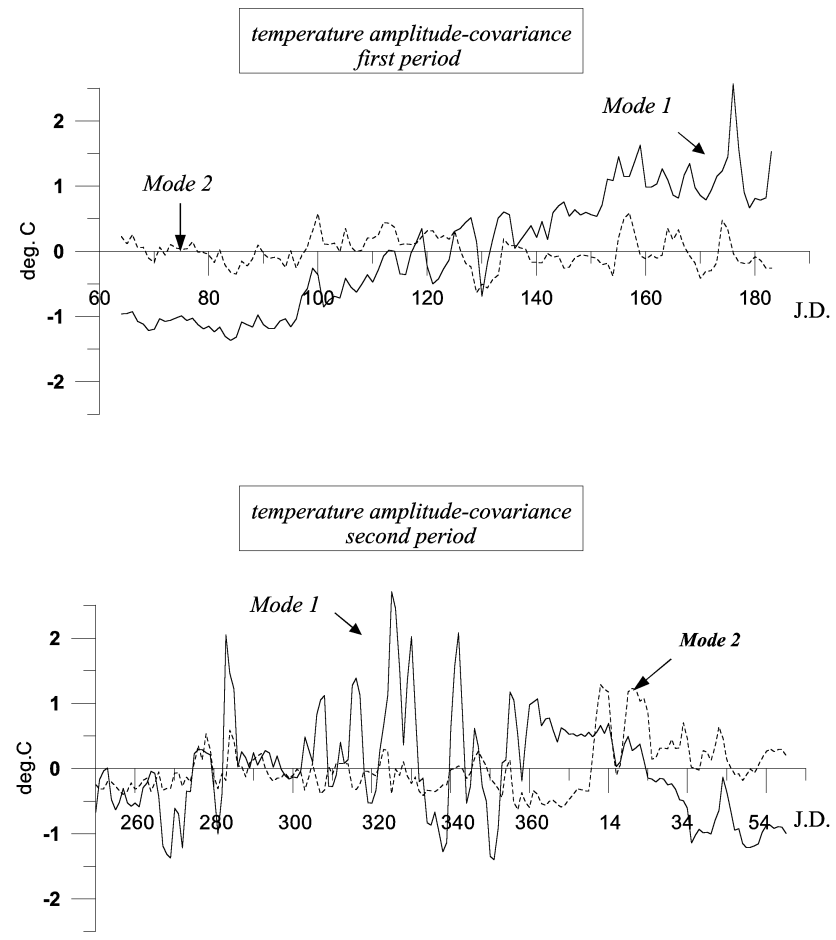

Fig. 13. Temperature amplitude time series for the whole period of measurements (04 March 2000 - 01 March 2001; J.D. 64 - J.D. 60).

Sea, which consists of basin, sub-basin scale and mesoscale dynamical structures. The last one is characterised by two gyres (anticyclonic and cyclonic) with dimensions of about 100 and $50 \mathrm{~km}$, respectively, (see Fig. 14) that move together as a dipole. This feature is the prominent characteristic of the Cretan Sea circulation. Oscillations of the order of a month characterise the upper layer during the whole period of measurement, indicating the displacements of the dipole circulation system. This influence can be felt mainly in the 

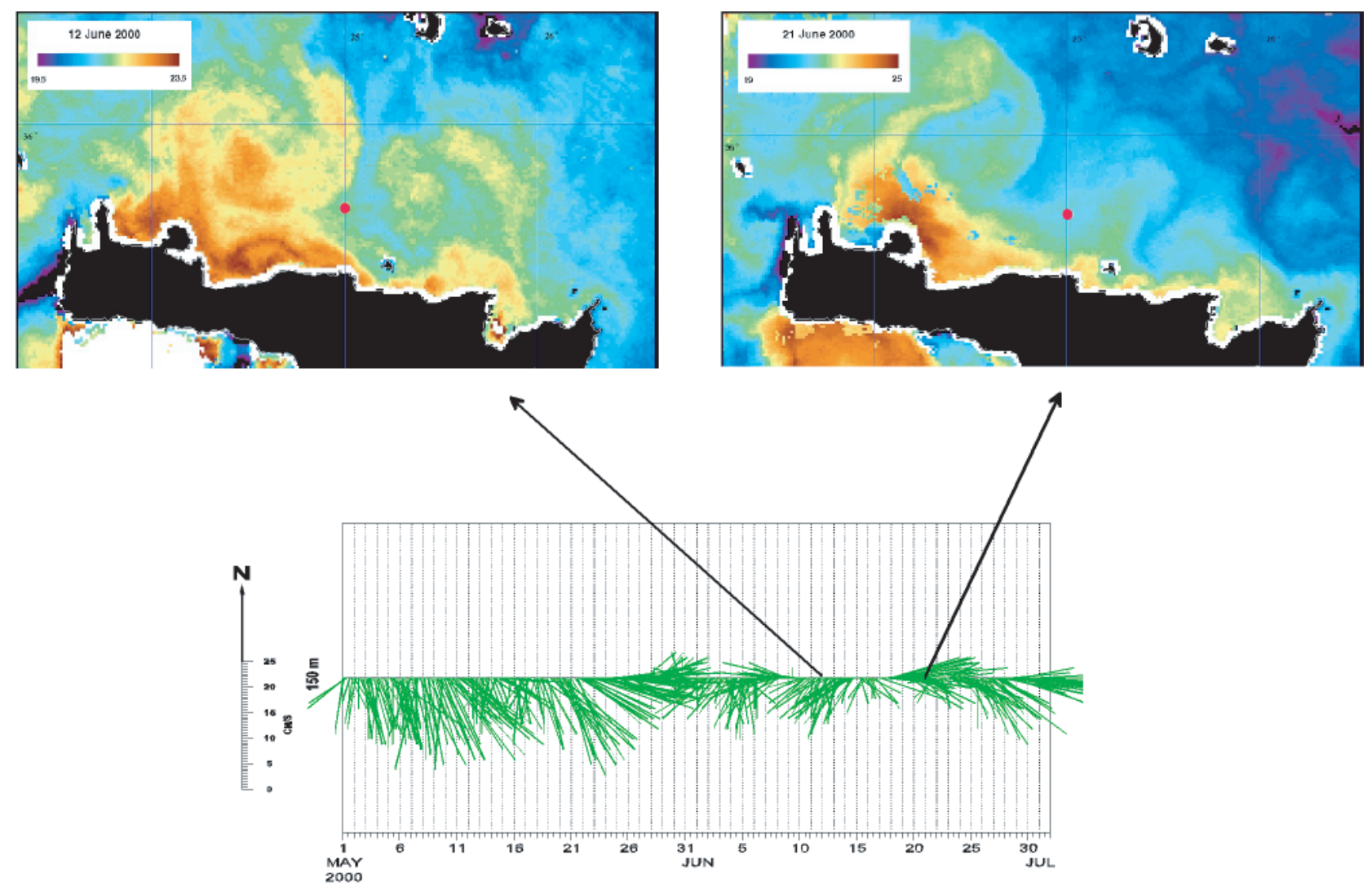

Fig. 14. Relation between SST Imageries and 150 m current time series during the first period (04 March 2000 - 01 July 2000 ; J.D. 64 - J.D. 183).

layer between 100 and $300 \mathrm{~m}$, and it is very well revealed by variations of the $15.5^{\circ} \mathrm{C}$ isotherm depth. As far as the intermediate layer is concerned, it also shows "high-frequency oscillations" but seems to be strongly influenced by a basinwide cyclonic circulation, which manifests itself in the form of the low-frequency seasonal upwelling modulated by the high-frequency oscillations.

From the heat and buoyancy loss point of view, which reflect the air-sea interaction processes in the area, winter $99 / 00$ was stronger than winter $00 / 01$; as a consequence, the convective mixing depth extends to $\sim 250 \mathrm{~m}$ during the first winter compared to $\sim 100-150 \mathrm{~m}$ convection depth observed during the second one. This limited convection depth was also observed in the mid 1990s by Theocharis et al. (1999b) and explained in terms of the enhanced vertical density stratification. In his work, he mentioned that in the past the homogenization of the entire water column was possibly considered.

The coupling of this complex water mass regime with the important synoptic variability of circulation patterns is responsible for the strongly varying salinity throughout the measuring period. Time series of salinity indicates a patchy structure and the water column seems to be influenced by the intrusion of high and low salinity waters in the intermediate layer and the upper layer, respectively. Salinity minimum occurring within the upper $200 \mathrm{~m}$ layer indicates tran- sient intrusion of the AW. This water may have its origin in the southwest regions of the Ionian Sea (Lascaratos, 1992; Theocharis et al., 1999b) and recirculating in the eastern part flowing along the cyclone's meandering boundary. The synoptic variability is characterised by episodes of strong horizontal and vertical advection that creates pulses of fresh or saline water mainly at the surface and at the CIW interface $(150 \mathrm{~m})$. The time scale of these pulses is associated with the mesoscale variability, being certainly larger than those issuing from the internal waves triggered over the straits. At the seasonal time scale, a development of the surface saline layer during the summer period follows the seasonal thermocline formation.

As was mentioned before, the change in the direction of the currents can be attributed to the circulation system consisting of the W. Cretan Anticyclone and Cretan Cyclone, present in the area (Fig. 1), and whose behaviour can be defined as a dipole. These mesoscale features seem to control the circulation of the Cretan Sea, as already mentioned by Georgopoulos et al. (2000). The current field variability associated with a dipole structure is intensified at intermediate depths between about $90 \mathrm{~m}$ and $250 \mathrm{~m}$. However, two situations were identified from the temperature field when the influence of the dipole structure extends down to the maximum measurement depth, i.e. 500 m (J.D. 150 and J.D. 360). The mooring system seems to be positioned in between the 
two gyres and thus in the area of a southward flow. When the mesoscale dipole shifts the current changes and/or reverses direction. Synoptic time scale current variability appears closely related to horizontal displacement of the dipole system, as appears evident from Fig. 14. On 12 June 2000, the position of the mooring coincided with the boundary zone of the cyclonic and anticyclonic gyres and the recorded current was mainly southward. On the other hand, ten days later, i.e. 21 June 2000 , the dipole moved westward by about $50 \mathrm{~km}$, leaving the buoy close to the southern limit of the cyclonic gyre, resulting in the change of current direction with prevailing eastward currents.

As far as the vertical velocities are concerned, it can be seen that in most cases in the surface layer, the downward velocities coincide with the presence of the anticyclonic gyre in the mooring area and vice versa, being in agreement with the patterns seen in the temperature field. The velocity time series are biased by high-frequency oscillation $(24 \mathrm{~h})$, which might not represent real water motion but vertical zooplankton migration through the water column. In general, the layer between about $80 \mathrm{~m}$ and $250 \mathrm{~m}$ appears highly coherent, while surface and deeper layers appeared decoupled from this intermediate one.

The application of the EOF analysis evidences the first mode, which accounts for most of the variance (about almost $90 \%$ ), and is fairly barotropic. On the other hand, the depthdependent mode shows a depth structure similar to the first baroclinic mode with a zero crossing at about $250 \mathrm{~m}$. The displacements of the mesoscale dipole are well reflected in the time variability of the barotropic-like mode of both zonal and meridional velocity components.

As far as the temperature EOF analysis is concerned, the seasonal heating seems to be the most important feature, as seen by the trend observed in the first mode. However, some other less intense processes associated with passages of mesoscale eddies could be masked by this strong signal. The influence of the seasonal heating can be removed by calculating the EOF function using the correlation instead of the covariance matrix. The surface layer heating (down to $\cong 65 \mathrm{~m}$ ) during spring and summer accounts for almost $90 \%$ of the total temperature variance in the first period, decreasing in intensity during the second period of measurement (73\%), only because the $45 \mathrm{~m}$ measurements were not available at that time.

\section{Concluding remarks}

The buoy site is located between two major mesoscale features in the Cretan Sea, an anticyclonic eddy in the west and a cyclonic eddy in the east; their combined action governed the circulation in the area. These two gyres move as a mesoscale dipole structure and their displacement affects the water column, inducing upwelling or downwelling processes. The dipole structure influence is intensified in the layer between 100 and $250 \mathrm{~m}$, but in some cases it extends down to at least $500 \mathrm{~m}$. Due to the mooring position, the current field is dom- inated by a very stable flow regime towards the SE and ESE directions.

The important synoptic variability of the circulation patterns is responsible for the strongly varying characteristics of the temperature and salinity throughout the measuring period. The application of the EOF analysis indicated that the structure of the water column is mainly depth-independent; whereas a baroclinic-like structure shows that the upper layer (above $200 \mathrm{~m}$ ) is out of phase with respect to the layer beneath. Contrary to the previous study conducted in the mid 1990s, the strongest velocities were observed during autumn and winter and not during summer. The temperature field shows oscillations of the order of a month, which characterise the upper layer during the whole period of measurement. On the other hand, the intermediate layer shows oscillations of the order of 20 days, during spring, summer and autumn, but contrary to the upper layer, this layer seems to be influenced by a basin-wide cyclonic circulation generating upwelling, rather than by the mesoscale structure displacement.

Further data analysis and correlation with AHVRR images are in progress, which will permit one to define the spatial influence of the gyres in the mooring area.

Acknowledgements. The work was carried out in the framework of the Mediterranean Forecasting System - Pilot Project (MFS-PP) funded by the European Union DGXII under the MAST3 Program (contract No MAS3-CT98-0171). The authors are very thankful to Mr. Corrado Fragiacomo for his contribution with the Figures' design.

Topical Editor N. Pinardi thanks a referee for her/his help in evaluating this paper.

\section{References}

Georgopoulos, D., Theocharis, A., and Zodiatis, G.: Intermediate water formation in the Cretan Sea (S. Aegean Sea), Oceanologica Acta, 9, 239-359,1989.

Georgopoulos, D., Chronis, G., Zervakis, V., Lykousis, V., Poulos, S., and Iona, A.: Hydrology and circulation in the Southern Cretan Sea during the CINCS experiment (May 1994-September 1995), Progress in Oceanography, 46, 89-112, 2000.

Hopkins, T. S.: Physical processes in the Mediterranean basins, in: Estuarine transport processes, South Carolina, USA, (Ed) Kjerfve, B., University of South Carolina Press, 269-310, 1978.

Kundu, P., Allen, J. S., and Smith, R.: Modal decomposition of the velocity field near the Oregon coast, J. Phys. Ocean., (5), 683704, 1975.

Kundu, P. K. and Allen, J. S.: Some three-dimensional characteristics of low-frequency current fluctuations near the Oregon Coast, J. Phys. Oceanogr., 6, 181-199, 1976.

Lacombe, H. and Tchernia, P.: Quelques Traits Generaux de l'Hydrologie Mediterranee, Cahiers Oceanographiques, 12, 527547, 1960.

Lascaratos, A.: Hydrology of the Aegean Sea, in: Winds and currents of the Mediterranean Basin, (Ed) Charnock, H., pp. 313334, Nato Advanced Science Institute: atmospheric and oceanic circulation in the Mediterranean Basin, Reports in Meteorology and Oceanography, Harvard University no. 40, 1, 1992. 
Malanotte-Rizzoli, P., Manca, B. B., Ribera d'Alcalà, M., Theocharis, A., Bergamasco, A., Bregant, D., Budillon, G., Civitarese, G., Georgopoulos, D., Michelato, A., Sansone, E., Scarazzato, P., Souvermezoglou, E., in: A synthesis of the Ionian Sea hydrography, circulation and water mass pathways during POEM-Phase I, Progress in Oceanography, 39, 153-204, 1997.

Nittis, K., Tziavos, C., Thanos, L., Drakopoulos, P., Cardin, V., Gačić, M., Petihakis, G., and Basana, B., in: The Mediterranean Moored Multi-sensor Array (M3A): System development and initial results, Ann. Geophysicae, this issue, 2003.

Preisendorfer, R. W.: Principal Component Analysis in Meteorology and Oceanography, (Ed) Curtis, D., Mobley pp. 419, 1988.

Roether, W., Manca, B., Klein, B., Bregant, D., Georgopoulos, D., Beitzel, V., Kovačevic, V., and Luchetta, A.: Recent changes in the Eastern Mediterranean deep waters, Science, 271, 333-335, 1996.

Schott, F. and Leaman, K.: Observations with Moored Acoustic Doppler Current Profilers in the convection Regime in the Golfe du Lion, J. Phys. Oceanogr., 21, 558-574, 1991.

The POEM Group: General Circulation of the Eastern Mediterranean, Earth Science Reviews, 32, 285-309, 1992.

Theocharis, A.: Deep Water formation and circulation in the Aegean Sea, in: Winds and currents of the Mediterranean basins, Proceedings of the Workshop held at Santa Teresa, La Spezia, Italy. NATO Advanced Science Institute (ASI). Atmospheric and Oceanic Circulation in the Mediterranean Basin, 7-14 September 1983, Harvard University Report in Meteorology and Oceanography, 41, 1, 335-359, 1992.
Theocharis, A. and Georgopoulos, D.: Dense water formation over the Samothraki and Limnos Plateaux in the North Aegean Sea (Eastern Mediterranean Sea), Continental Shelf Research, 13 (8/9), 919-939, 1993.

Theocharis, A., Kontoyiannis, H., Balopoulos, E., and Georgopoulos, D.: Climatological changes in the Cretan Sea (south Aegean Sea) leading to the new hydrological regime of the deep waters in the eastern Mediterranean, Proceedings of a TOS Scientific Meeting: The role of the Ocean in Global Change Research, Amsterdam 8-11 July 1996, 35, 1996.

Theocharis, A., Nittis, K., Kontoyiannis, H., Papageorgiou, E., and Balopoulos, E.: Climatic changes in the Aegean Sea influence the Eastern Mediterranean thermohaline circulation (19861997), Geophys. Res. Lett., 26(11): 1617-1620, 1999a.

Theocharis, A., Balopoulos, E., Kioroglou, S., Kontoyiannis, H., and Iona, A.: A synthesis of the circulation and hydrography of the South Aegean Sea and the Straits of the Cretan Arc (March 1994-January 1995), Progress in Oceanography, 44, 469-509. 1999b.

Schott, F. and Leaman, K. D.: Observations with Moored Acoustic Doppler Current Profilers in the Convection Regime in the Golfe du Lion, Am. Meteo. Soc., 21, 558-574, 1991.

Schlitzer, R., Roether, W., Oster, H., Junghans, H. G., Johannsen, H., and Michelato, A.: Chlorofluoromethane and oxygen in the Eastern Mediterranean, Deep Sea Res., 38, 1531-1551, 1991.

Wüst G.: On the vertical circulation of the Mediterranean Sea, J. Geophys. Res., 66, 3261-3271, 1961. 